Check for updates

Cite this: RSC Adv., 2019, 9, 23425

\title{
Specific purification of a single protein from a cell broth mixture using molecularly imprinted membranes for the biopharmaceutical industry $\dagger$
}

\author{
Wenyuan Xie, (D) *ad Honglei Wang, ${ }^{\text {b }}$ Yen Wah Tong, ${ }^{\text {*bc }}$ Niranjani Sankarakumar, ${ }^{\text {b }}$ \\ Ming Yin, ${ }^{c}$ Defeng Wu (D) ${ }^{d}$ and Xiaoli Duan ${ }^{\mathrm{e}}$
}

A surface imprinting method is presented herein for the development of a highly selective yet highly permeable molecularly imprinted membrane for protein separation and purification. The resultant protein imprinted membrane was shown to exhibit great potential for the efficient separation of the template protein from a binary mixture and a cell lysate solution, while maintaining high transport flux for complementary molecules. Bovine Serum Albumin (BSA) and Lysozyme (Lys) were individually immobilized on a cellulose acetate membrane as template molecules. In situ surface crosslinking polymerization was then used for protein imprinting on the membrane for a controlled duration. Both membranes showed high adsorption capacity towards template proteins in the competitive batch rebinding tests. In addition, the adsorption capacity could be greatly enhanced in a continuous permeation procedure, where the resultant membrane specifically adsorbed the template protein for more than $40 \mathrm{~h}$. Moreover, this is the first report of purification of a specific protein from the cell broth mixture using a molecularly imprinted membrane. The protein imprinted membrane enables the transport of multiple non-template proteins with high permeation rate in a complex system, thus opening the way for high efficiency protein separation at a low cost for the industry.

Received 14th April 2019

Accepted 11th July 2019

DOI: $10.1039 / c 9 r a 02805 f$

rsc.li/rsc-advances separation of biomacromolecules due to their flexible, complex and large-sized structures. ${ }^{10} \mathrm{~A}$ major challenge lies in the limited mass transfer of the biomolecules in the bulk polymer, which hinders the templates' removal and targets' rebinding. The surface imprinting technique is one of the most efficient strategies to overcome this obstacle. ${ }^{11}$ Surface imprinted thin films could be employed as shell layers of various kinds of substrates, for instance, nanoparticles ${ }^{12-14}$ nanowires ${ }^{15-17}$ nanofibers, ${ }^{18}$ nanotubes ${ }^{19}$ and microspheres. ${ }^{20,21}$ However, further separation steps might be required, such as dispersion and recollection of core-shell particles in the protein solution.

Membrane separation has been widely used in industrial purification due to its single-step operation procedure, low energy consumption and ease of scaling-up. Besides, it has great potential in protein separation and purification based on the size, charge and other properties of proteins. ${ }^{22-24}$ However, most of membranes were not tailored specially for a particular protein. Besides, membrane properties were adapted specifically for each separation system. ${ }^{25}$

In contrast, molecularly imprinted membranes (MIMs) offer researchers opportunities to design membranes that are targeted to specific molecules. ${ }^{26,27}$ Thereby, a generic MIM can be employed for separating different protein mixtures and systems as long as the desired target molecules are the same. MIMs combine advantages of both the molecular imprinting technology (i.e. high intrinsic selectivity) and the membrane 
technology (i.e. low energy consumption, ease of scale-up and the potential for continuous operation). ${ }^{26}$ Recently, MIMs for protein separation have been reported with several strategies, including electrospinning, ${ }^{28}$ surface grafting ${ }^{29-31}$ and nanopores incorporation..$^{32}$ High specific recognition of the template proteins has been achieved. However, drawbacks such as weak binding force and low perm-selectivity, are still challenging the comprehensive membrane performance. ${ }^{33}$

Consequently, finding new approaches to construct the surface imprinted layer is of great importance to achieve new MIMs with excellent perm-selectivity for protein purification. Furthermore, the separation mechanism of MIMs in the continuous membrane separation process, which differs greatly from that of the static adsorption process, needs to be investigated systematically.

To address the above problems, we herein report a novel protein surface imprinting technique for the preparation of a protein imprinted membrane with high binding capacity to the template protein and high permeability to the non-template protein. Following a similar molecularly imprinting technique based on our previous works, ${ }^{34-36}$ the template protein was first covalently immobilized on a porous cellulose acetate membrane. Subsequently, redox initiators were spread onto the porous substrate by spin-coating, and then in situ crosslinking polymerization was carried out. Finally, the immobilized template protein was removed by hydrolysis to leave imprinted sites on the membrane (as shown in Fig. 1). In this study, two molecularly imprinted membranes, $\mathrm{MIM}_{\mathrm{BSA}}$ and $\mathrm{MIM}_{\mathrm{Lys}}$, were prepared by using bovine serum albumin (BSA) and lysozyme
(Lys) as template proteins respectively. The effectiveness of this method was examined through the separation of template proteins from the BSA-Lys binary mixture. In addition, membrane performance was tested in a continuous separation setup, with a complex mixture to simulate an industrial system, consisting of BSA, lysozyme and bacterial cell lysate. Furthermore, membrane separation mechanism of MIMs was investigated.

\section{Experimental section}

\section{Materials}

Cellulose acetate (CA) (CA-389-30) was purchased from Eastman Chemical Company, USA. Phosphate buffered saline (PBS, 0.1 $\mathrm{M})$, sodium periodate, bovine serum albumin (BSA), lysozyme (Lys), fluorescein isothiocyanate (FITC), methyl methacrylate (MMA), ethylene glycol dimethacrylate (EGDMA), ammonium persulfate (APS), sodium bisulfite (SBS), sodium dodecyl sulfate (SDS) and trifluoroacetic acid (TFA) were purchased from Sigma Aldrich, USA. N-methyl-2-pyrrolidone (NMP, 99.5\%) was purchased from Merck KGaA, Darmstadt, Germany. Tryptone, yeast extract and agar were purchased from BactoTM. Escherichia coli ATCC®19853 was purchased from the American Type Culture Collection, USA.

\section{Preparation of MIMs and NIMs}

Surface imprinting for $\mathbf{M I M}_{\mathbf{B S A}}$ and $\mathbf{M I M}_{\mathbf{L y s}}$. The substrate porous membrane of cellulose acetate was prepared through phase inversion method. Aldehyde group was then chemically

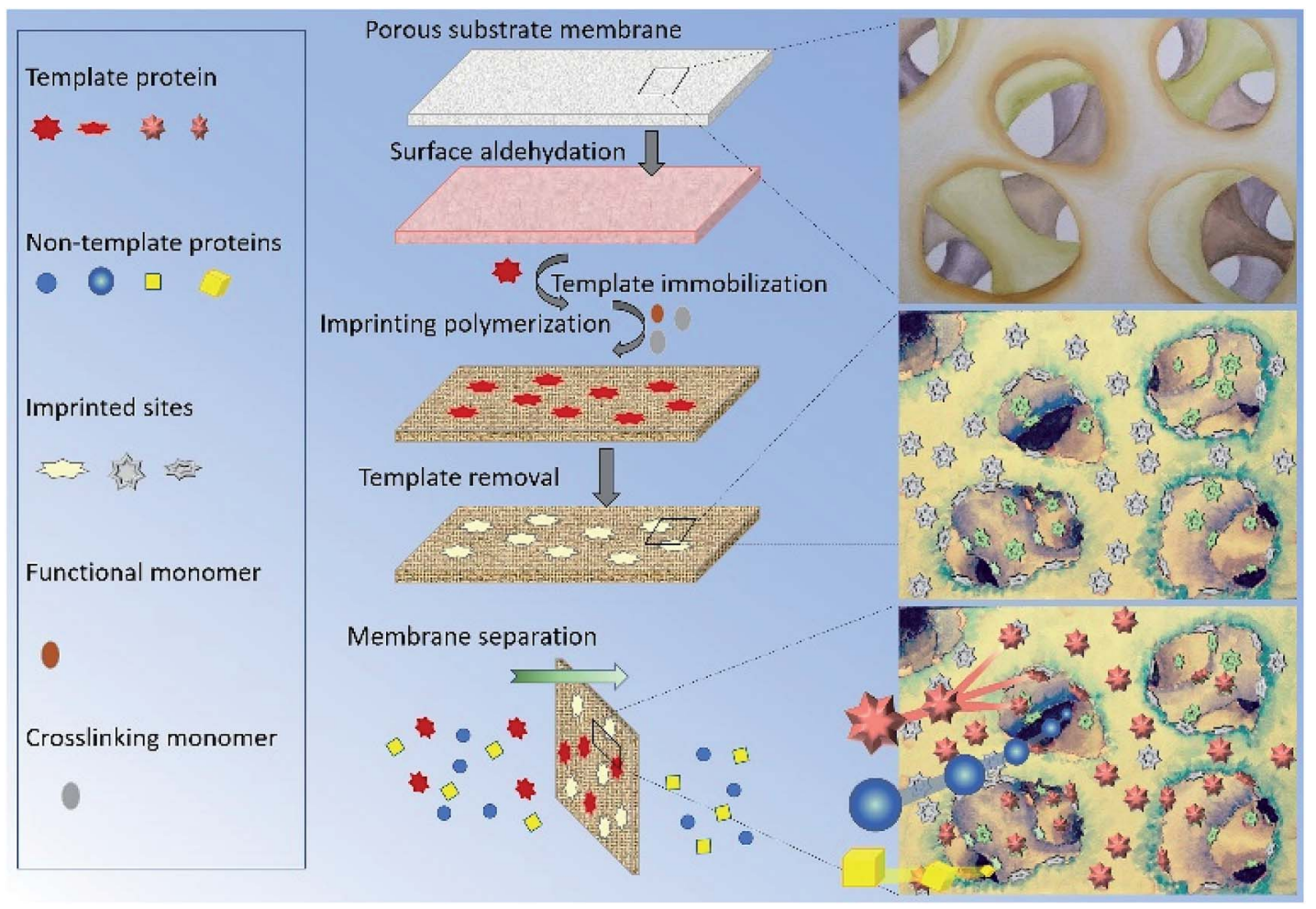

Fig. 1 Schematic diagram of preparation and separation of the protein-imprinted membrane. 
modified onto the membrane surface. After that, the template protein was covalently immobilized onto the porous substrate membrane. The preparation and optimization details of the protein immobilized membrane (BSA-immobilized membrane and lysozyme-immobilized membrane) can be found in the ESI. $\dagger$ Afterwards, methyl methacrylate (MMA, Sigma Aldrich) $(3.2 \mathrm{ml})$ and ethylene glycol dimethacrylate (EGDMA, Sigma Aldrich) (22.4 ml) were mixed at $40{ }^{\circ} \mathrm{C}$ under nitrogen. Ammonium persulfate (APS, Sigma Aldrich) and sodium bisulfite (SBS, Sigma Aldrich) (4 $\mathrm{mg} \mathrm{ml}^{-1}$ ) solutions were prepared separately and filtered through a poly(ether sulfone) filter with the pore size of $0.45 \mu \mathrm{m}$. The initiators were then coated onto the surface of the-BSA-immobilized membranes or the-lysozymeimmobilized membranes using a spin-coater (Laurel MSC650) under nitrogen. $4 \mathrm{ml}$ of the initiator solution was used for coating of each membrane. And the resultant membrane was immediately dipped into the monomer solution for the redox polymerization in a water bath $\left(40{ }^{\circ} \mathrm{C}\right)$. The duration of the polymerization reaction was adjusted to control the thickness of the molecularly imprinted polymer layer. Upon completion, the membranes were washed twice with $10 \%$ sodium dodecyl sulfate (SDS, Sigma Aldrich) to remove any remaining monomers and several times with de-ionized water to remove the remaining SDS.

Template removal. The immobilized template BSA or lysozyme molecules were removed by acid hydrolysis. Membranes prepared above were shaken in $1 \mathrm{M}$ sulfuric acid. A sample of the acid was analyzed hourly using UV-vis spectrophotometry (Biochrom Libra S32) until no change in the absorption was detected, indicating that all of the template protein molecules had been removed. Upon completion, the membrane was washed with de-ionized water until the $\mathrm{pH}$ of the washing water was close to neutral.

Preparation of non-imprinted membrane (NIM). NIMs were prepared as control. Preparation of NIMs follows that of MIMs described above except that no template protein was used. The polymerization duration of NIM $_{\mathrm{BSA}}$ was the same with $\mathrm{MIM}_{\mathrm{BSA}}$, and polymerization duration of $\mathrm{NIM}_{\mathrm{Lys}}$ was the same with MIM $_{\text {Lys }}$.

\section{Structural characterization of membranes}

Membrane structures before and after aldehyde functionalization were monitored using a FTIR Spectrum 2000 (PerkinElmer) with an attenuated total reflection (ATR-FTIR) technique. The surface elemental composition of the membranes after each surface modification step were determined through X-ray photoelectron spectroscopy (XPS) (AXIS HIS, 165 Ultra, Shimadzu). Surface roughness changes of membranes after each modification step were analyzed using a Nanoscope IIIa AFM (Veeco) in tapping mode. Morphological observation of the membranes was conducted using a field emission scanning electron microscopy (FESEM) (JSM-6700F, JEOL). Membranes were first freeze-dried and then fractured in liquid nitrogen. The fractured membranes were then mounted onto the sample holder using conductive carbon adhesive tape. The samples were sputtered with platinum before FESEM observation. The nitrogen distribution of the protein-adsorbed membranes was measured using an energy dispersive X-ray (EDX, Oxford Instruments, Aztec X-Max ${ }^{\mathrm{N}}$ ). All EDX analyses were performed using the line scan mode for $150 \mathrm{~s}$ along the cross-section of the MIMs. The pore size of the original CA membrane, MIMs and NIMs were characterized via neutral solute rejection by using a dead-end permeation cell, and detailed technical descriptions can be found in the ESI. $\dagger$

\section{Membrane performance characterization}

Protein rebinding tests. In the membrane adsorption experiment of $\mathrm{MIM}_{\mathrm{BSA}}, 10 \mathrm{ml}$ of $0.1 \mathrm{M}$ PBS (phosphate buffered saline, Sigma Aldrich) solution was used to prepare the BSA solution with an initial concentration of $2.5 \mathrm{mg} \mathrm{ml}^{-1}$ (36 nmol $\mathrm{ml}^{-1}$ ). The $\mathrm{MIM}_{\mathrm{BSA}}$ was shaken in the BSA solution at room temperature for $24 \mathrm{~h}$. The amount of BSA adsorbed by the tested membrane after $24 \mathrm{~h}$ was determined via eqn (S1) (see $\mathrm{ESI}_{\dagger} \dagger$ ). BSA concentrations in the solution before and after rebinding were determined using Agilent 1200 series HPLC with a C18, 4.6 $\times 250 \mathrm{~mm}$, reversed phase column (Grace Vydac, Alltech). Samples were prefiltered with a $0.2 \mu \mathrm{m}$ filter before analyzed by HPLC. Two mobile phases, (A) ultrapure water with $0.1 \mathrm{vol} \%$ trifluoroacetic acid (TFA, Sigma Aldrich) and (B) $80 \mathrm{vol} \%$ acetonitrile (Fisher Scientific) and $20 \mathrm{vol} \%$ water with $0.09 \mathrm{vol} \%$ TFA, were used for linear gradient elution. The flow rate of the

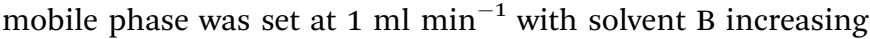
from 25 to $36 \%(\mathrm{v} / \mathrm{v})$ in $10 \mathrm{~min}$. The analyte injection volume was $40 \mu \mathrm{l}$ and the column temperature was set at $40{ }^{\circ} \mathrm{C}$. Samples were analyzed by UV-vis absorption at a wavelength of $220 \mathrm{~nm}$. The NIM $_{\text {BSA }}$ were also subjected to the same rebinding test for control purposes. The protein rebinding test of $\mathrm{MIM}_{\mathrm{Lys}}$ is the same with that of MIM $_{\mathrm{BSA}}$ except that $0.54 \mathrm{mg} \mathrm{ml}^{-1}$ (36 nmol $\mathrm{ml}^{-1}$ ) lysozyme solution was used instead of $2.5 \mathrm{mg} \mathrm{ml}^{-1}$ (36

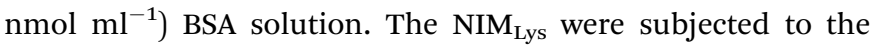
same rebinding test for control purpose. All tests were conducted in triplicate.

Adsorption kinetics study. Adsorption kinetics of MIMs and NIMs were studied using an experimental procedure similar to that of the single rebinding test. The initial BSA concentration was $2.5 \mathrm{mg} \mathrm{ml}^{-1}$ for $\mathrm{MIMI}_{\mathrm{BSA}}$ and $\mathrm{NIM}_{\mathrm{BSA}}$, and the initial lysozyme concentration was $0.54 \mathrm{mg} \mathrm{ml}^{-1}$ for MIM $_{\text {Lys }}$ and NIM $\mathrm{Nys}_{\text {L }}$. Analytes were drawn from the systems at regular intervals for HPLC analysis. The protein concentration obtained with HPLC were used to determine the adsorption profiles of the membranes over time. The tests were conducted in triplicate.

Adsorption isotherm study. 0.1 M PBS (phosphate buffered saline, Sigma Aldrich) solution was used to prepare the BSA solutions with various initial concentrations. The $\mathrm{MIM}_{\mathrm{BSA}} /$ $\mathrm{NIM}_{\mathrm{BSA}}$ with a membrane area of $1.77 \mathrm{~cm}^{2}$ was incubated in $10 \mathrm{ml}$ of the BSA solution with a certain protein concentration at room temperature for $24 \mathrm{~h}$ to reach equilibrium. The protein adsorption capacity at equilibrium $\left(Q_{\mathrm{e}}\right)$ was estimated by measuring the variation of the protein concentration before and after adsorption through UV-vis Absorption Spectroscopy (Biochrom Libra S32). Same experiments were conducted with $\mathrm{MIM}_{\text {lys }}$ and $\mathrm{NIM}_{\text {lys }}$ using lysozyme solutions. Data was fitted to 
the Langmuir isotherm with eqn (1) and to the Freundlich isotherm with eqn $(2)^{37}$

$$
Q_{\mathrm{e}}=\frac{C_{\mathrm{e}} \times Q_{\max }}{k_{\mathrm{d}}+C_{\mathrm{e}}}
$$

where $Q_{\mathrm{e}}$ is the protein adsorption capacity at equilibrium in $\mathrm{nmol} \mathrm{cm}{ }^{-2}, C_{\mathrm{e}}$ is the free protein concentration in the equilibrium solution in $\mathrm{nmol} \mathrm{ml}^{-1}, Q_{\max }$ is the maximum adsorption capacity of the template protein in $\mathrm{nmol} \mathrm{cm}{ }^{-2}, k_{\mathrm{d}}$ is the dissociation constant in $\mathrm{nmol} \mathrm{ml}^{-1}$

$$
\lg Q_{\mathrm{e}}=\lg A+m \times \lg C_{\mathrm{e}}
$$

where $Q_{\mathrm{e}}$ and $C_{\mathrm{e}}$ are the same with that in eqn (1), $A\left(\mathrm{nmol} \mathrm{cm}{ }^{-2}\right)$ and $m$ are Freundlich parameters.

Competitive batch rebinding tests. In the competitive batch rebinding test, separation factors of the MIMs were studied in a BSA-Lysozyme binary solution in a $0.1 \mathrm{M}$ PBS solution with initial BSA concentration of $2.5 \mathrm{mg} \mathrm{ml}^{-1}$ and Lys concentration of $0.54 \mathrm{mg} \mathrm{ml}{ }^{-1}$ respectively. The $\mathrm{MIM}_{\mathrm{BSA}}$ or $\mathrm{MIM}_{\mathrm{Lys}}$ with a surface area of $1.77 \mathrm{~cm}^{2}$ was shaken for $24 \mathrm{~h}$ in $10 \mathrm{ml}$ of the binary protein solution. Afterwards, the binary solution was analyzed by HPLC using the same procedure described for the batch rebinding experiment. NIMs were tested with the same procedure. All the competitive batch rebinding tests were conducted in triplicate.

The separation factor of $\mathrm{MIM}_{\mathrm{BSA}}$ and $\mathrm{NIM}_{\mathrm{BSA}}$ was expressed as eqn $(3)^{38}$ and the separation factor of MIM $_{\mathrm{Lys}}$ and $\mathrm{NIM}_{\mathrm{Lys}}$ was expressed as eqn $(4)^{39}$

$$
\begin{aligned}
\alpha_{\mathrm{BSA} / \mathrm{Lys}} & =\frac{\left(C_{\mathrm{f}, \mathrm{BSA}}-C_{\mathrm{r}, \mathrm{BSA}}\right) /\left(C_{\mathrm{f}, \mathrm{Lys}}-C_{\mathrm{r}, \mathrm{Lys}}\right)}{C_{\mathrm{f}, \mathrm{BSA}} / C_{\mathrm{f}, \mathrm{Lys}}} \\
\alpha_{\mathrm{Lys} / \mathrm{BSA}} & =\frac{\left(C_{\mathrm{f}, \mathrm{Lys}}-C_{\mathrm{r}, \mathrm{Lys}}\right) /\left(C_{\mathrm{f}, \mathrm{BSA}}-C_{\mathrm{r}, \mathrm{BSA}}\right)}{C_{\mathrm{f}, \mathrm{Lys}} / C_{\mathrm{f}, \mathrm{BSA}}}
\end{aligned}
$$

where $C_{\mathrm{f}, \mathrm{BSA}}\left(\mathrm{nmol} \mathrm{ml} \mathrm{m}^{-1}\right)$ is the BSA concentration in the feed solution, $C_{\mathrm{r}, \mathrm{BSA}}\left(\mathrm{nmol} \mathrm{ml}^{-1}\right)$ is the concentration of BSA in the solution after $24 \mathrm{~h}$ of competitive batch rebinding, $C_{\mathrm{f}, \mathrm{Lys}}$ (nmol $\mathrm{ml}^{-1}$ ) is the Lysozyme concentration in the feed solution, and $C_{\mathrm{r}, \mathrm{Lys}}\left(\mathrm{nmol} \mathrm{ml} \mathrm{m}^{-1}\right.$ ) is the concentration of Lysozyme in the solution after $24 \mathrm{~h}$ of competitive batch rebinding.

Permeation study with BSA-Lys binary solution. The membrane performance in the protein permeation experiment was studied with a dialysis permeation cell consisting of one feed chamber and one strip chamber (Fig. S1, see ESI $\dagger$ ). The membrane sample was clamped between these two chambers. ${ }^{40}$ The feed solution was a BSA-Lys binary mixture in $0.1 \mathrm{M}$ PBS solution with initial concentration of $36 \mathrm{nmol} \mathrm{ml}^{-1}$ for BSA and Lys respectively. The strip solution was a $0.1 \mathrm{M}$ PBS solution. Both solutions were stirred at $80 \mathrm{rpm}$ using Teflon impellers. $0.5 \mathrm{ml}$ of samples from the feed and the strip chambers were collected periodically for HPLC analysis separately. The tests were conducted in triplicate. Protein permeation rate $J$ (nmol $\mathrm{cm}^{-2} \mathrm{~h}^{-1}$ ) of the membranes was defined as:

$$
J=\frac{V \times \Delta C_{\mathrm{P}}}{A \times \Delta t}
$$

where $\left.\Delta C_{\mathrm{P}}(\mathrm{nmol} \mathrm{m})^{-1}\right)$ is the concentration change of the solute in the strip chamber, $\Delta t(\mathrm{~h})$ is the permeation time, $V(\mathrm{ml})$ is the stripping volume, and $A\left(\mathrm{~cm}^{2}\right)$ is the effective membrane area, which is $1.77 \mathrm{~cm}^{2}$ in this experiment.

Preparation of bacterial lysate solution. Medium including solid media and liquid media were prepared as follows. Bottom agar solid media was prepared by firstly mixing $1 \mathrm{~g}$ of tryptone (BactoTM), $0.5 \mathrm{~g}$ of yeast extract (BactoTM), $1 \mathrm{~g}$ of sodium chloride (Merck KGaA, Darmstadt, Germany) and $1.5 \mathrm{~g}$ of agar (BactoTM) with $100 \mathrm{ml}$ DI water. The mixture was then autoclaved for the purpose of sterilization. At a temperature of $50{ }^{\circ} \mathrm{C}$, the medium was poured into sterile disposable Petri dishes and allowed to solidify. The same procedure was repeated for preparing the top agar medium having $0.5 \%$ of agar. The liquid broth medium was also prepared in a similar fashion without the addition of the agar for propagating the host bacterium. The bacterium used in this study was Escherichia coli ATCC®19853. A starter culture of the bacteria was prepared by picking an isolated colony from stock agar plates and grown for $6 \mathrm{~h}$. A $50 \mathrm{ml}$ broth culture was prepared by inoculating with $0.5 \mathrm{ml}$ of the $6 \mathrm{~h}$ culture and grown for $18 \mathrm{~h}$. All the broth cultures were grown at $37^{\circ} \mathrm{C}$ while shaking at $300 \mathrm{rpm}$. The cells were then collected by centrifuging at $9000 \mathrm{rpm} .10 \mathrm{ml}$ broth media was added for harvesting of the cells. Then, mixture of the cell and media was put into a $4{ }^{\circ} \mathrm{C}$ refrigerator followed by $1 \mathrm{~h}$ thawing at room temperature. The freeze-thaw cycles were repeated 3 times. Disruption of cells was performed using an ultrasonic processor (VCX 130, Sonics and Materials) at $20 \mathrm{kHz}$ equipped with a needle titanium alloy Ti-6Al-4V probe of $6 \mathrm{~mm}$ diameter and $113 \mathrm{~mm}$ length (Model CV18 6085). The disruption period was $3 \mathrm{~s}$ with $7 \mathrm{~s}$ intervals in an ice bath for $10 \mathrm{~min}$ and the acoustic power was $91 \mathrm{~W}$. Subsequently, the mixture of bacterial lysate and the culture medium was filtered using a membrane with pore size of $0.22 \mu \mathrm{m}$ and stored at $4{ }^{\circ} \mathrm{C}$ for future use. The concentration of the resultant lysate solution (in $\mathrm{mg} \mathrm{ml}^{-1}$ ) was tested through weighting the residue after drying the solution.

Permeation study with a complex protein mixture. The permeation study with a complex protein mixture was carried out with the dialysis permeation cell. $1 \mathrm{ml}$ of bacterial lysate solution prepared above was added into $34 \mathrm{ml}$ of BSA-Lys binary solution with an initial BSA and Lys concentration of $36 \mathrm{nmol}$ $\mathrm{ml}^{-1}$ respectively to prepare the feed solution. The strip solution was a $0.1 \mathrm{M}$ PBS solution. Both solutions were stirred at $80 \mathrm{rpm}$ using Teflon impellers. $0.5 \mathrm{ml}$ samples of both strip and feed solutions were collected periodically for HPLC analysis. The tests were conducted in triplicate. The concentration of BSA, lysozyme and bacterial lysate in each sample were tested by HPLC and calculated by Peak Fitting Module of Origin software. Permeation rates of BSA and Lys were defined in eqn (5). Permeation rate of bacterial lysate $J_{\text {Bac }}\left(\mathrm{mg} \mathrm{cm}^{-2} \mathrm{~h}^{-1}\right)$ were defined in eqn (6):

$$
J_{\mathrm{Bac}}=\frac{V \times \Delta C_{\mathrm{Bac}}}{A \times \Delta t}
$$

where $\Delta C_{\mathrm{Bac}}\left(\mathrm{mg} \mathrm{ml}^{-1}\right)$ is the bacterial lysate concentration change of the solute, $\Delta t(\mathrm{~h})$ is the permeation time, $V(\mathrm{ml})$ is the 
stripping volume and $A\left(\mathrm{~cm}^{2}\right)$ is the effective membrane area, which is $1.77 \mathrm{~cm}^{2}$ in this experiment.

\section{Results and discussion}

\section{Synthesis of membranes}

Cellulose acetate (CA) membrane was used as the substrate for surface chemical modification. The fabrication of the MIM began by immobilizing the template protein onto the CA membrane substrate. The appearance of the characteristic aldehyde peak at $\sim 1720 \mathrm{~cm}^{-1}$ in the FTIR spectrum proved the successful modification of the membrane using $\mathrm{NaIO}_{4}$-generated aldehyde groups from the hydroxyl groups of the CA (Fig. S2 $†$ ). The maximum number of aldehyde groups on the CA membrane surface was generated to maximize the density of the immobilized proteins on the CA substrates (Fig. S3, see ESI $\dagger$ for details). Subsequently, an in situ surface crosslinking polymerization on the protein-immobilized CA membrane was applied and followed by hydrolysis to remove the template protein. The duration of the polymerization reaction was used to control the thickness of the imprinting polymer layer. Specifically, if the polymerization time was too short, the thickness of the polymer film may not be sufficient to imprint the shape of the template protein. On the contrary, an excessive polymerization imprinting time would form denser polymer monoliths that could completely cover and permanently entrap the template proteins. The AFM images of original CA membrane and a series of non-imprinted membranes (NIMs) in Fig. 2 indicate average roughness values of $1.7 \mathrm{~nm}$ before polymerization and 2.4, 3.2, 5.9 and $13.3 \mathrm{~nm}$ after polymerization for 5, 8, 14 and $18 \mathrm{~h}$ respectively. The thickness of the imprinted polymer layer after $14 \mathrm{~h}$ of polymerization was estimated to be around $4.2 \mathrm{~nm}$ by comparing with the average roughness of the original CA membrane, which suggests a high possibility of fully covering the BSA template as the hydrodynamic radius of BSA is $4.5 \mathrm{~nm}^{41}$ Therefore, the $8 \mathrm{~h}$ polymerization time was chosen in subsequent studies, to balance between efficiency of the imprinting process and the surface imprinting coverage for fabrication of the MIM $_{\mathrm{BSA}}$. By using a similar estimation, the $5 \mathrm{~h}$ polymerization provided a $0.7 \mathrm{~nm}$ imprinting polymer layer which was used to imprint the Lys template molecules with a hydrodynamic radius of $1.9 \mathrm{~nm} .{ }^{42}$ The reduction in nitrogen content detected after protein removal indicated that $83 \%$ and $75 \%$ of the immobilized template protein molecules was removed via acidic hydrolysis for both $\mathrm{MIM}_{\mathrm{BSA}}$ and $\mathrm{MIM}_{\mathrm{Lys}}$ respectively (Table S1†).

\section{Structural characterization}

FESEM images in Fig. 3 show the aldehyde functionalized membranes and of those after in situ crosslinking polymerization. The comparison among the more detailed morphologies in Fig. 3B, E and $\mathrm{H}$ suggests that both the substrate underlayer and the top skin layer of the post-imprinted membrane are slightly thicker and denser than those before imprinting. Such morphological change is more pronounced in $\mathrm{MIM}_{\mathrm{BSA}}$, indicating that the imprinting layer on $\mathrm{MIM}_{\mathrm{BSA}}$ is thicker than $\mathrm{MIM}_{\mathrm{Lys}}$. The comparison among Fig. 3C, F and I shows higher roughness on the surfaces of the membranes after imprinting. These morphological changes observed in the post-imprinted membrane suggests that in situ crosslinking polymerization might have taken place on both the skin layer and the substrate under layer due to the porous structural nature of the membrane.

\section{Membrane performance}

Protein batch rebinding tests. Protein batch rebinding tests of MIMs and NIMs were performed at an initial template protein concentration of $36 \mathrm{nmol} \mathrm{ml}^{-1}$. More template proteins were observed to be adsorbed on MIMs than on NIMs (Fig. S4 $\dagger$ ). The saturated adsorption amount of BSA on MIM $_{\mathrm{BSA}}$ was 5.8 $\mathrm{nmol} \mathrm{cm}^{-2}$, which was about 6-fold higher than that of the
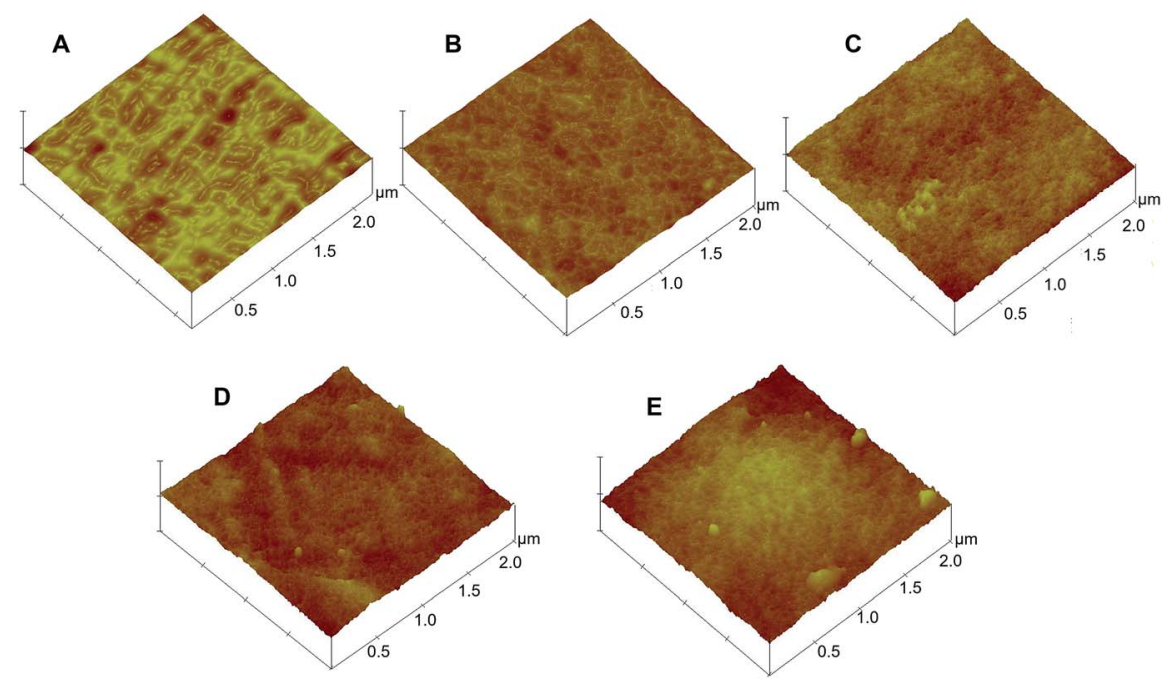

Fig. 2 Surface morphology of membranes by atomic force microscopy (AFM): (A) original CA membrane, and NIMs with various polymerization duration of (B) 5 h; (C) 8 h; (D) 14 h; (E) $18 \mathrm{~h}$. 

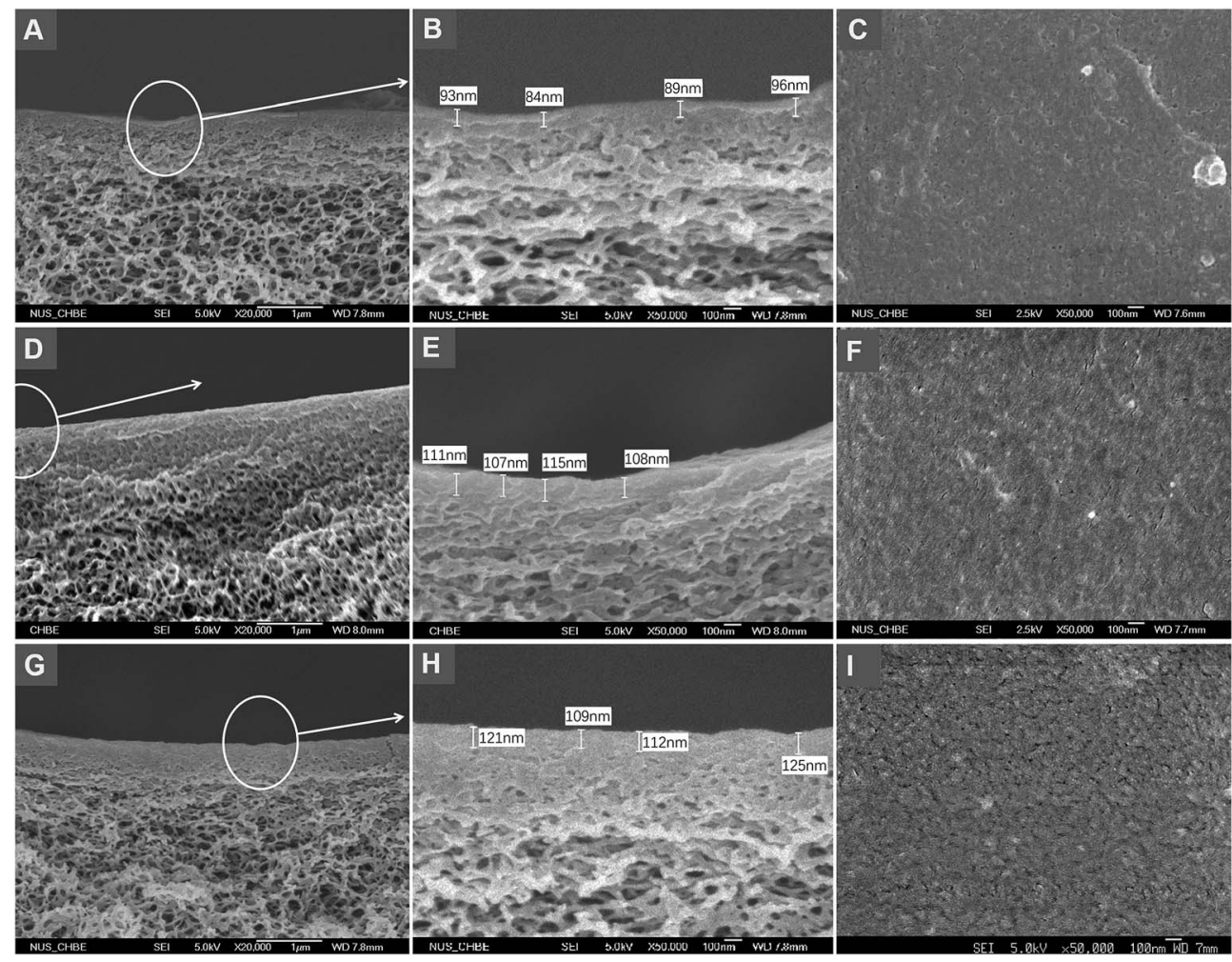

Fig. 3 Membranes morphology by FESEM. The cross-sections ( $A$ and $B$ ) and the top surface $(C)$ of the aldehyde functionalized membrane; the cross-sections ( $D$ and $E$ ) and the top surface $(F)$ of the MIMLys; the cross-sections ( $G$ and $H$ ) and the top surface (I) of the MIMBSA.

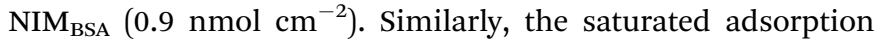
amount of lysozyme on $\mathrm{MIM}_{\mathrm{Lys}}$ was $4.0 \mathrm{nmol} \mathrm{cm}{ }^{-2}$, which was about 3.6-fold higher than that of $\operatorname{NIM}_{\mathrm{Lys}}\left(0.7 \mathrm{nmol} \mathrm{cm}{ }^{-2}\right)$. Thus, both of the protein imprinted membranes exhibit high affinities towards the template molecules. Based on the saturated adsorption amounts of MIMs and NIMs, the imprinting efficiency can be calculated as eqn (7): ${ }^{43}$

$$
E=\frac{C_{\mathrm{m}}-C_{\mathrm{n}}}{Q_{\mathrm{i}}} \times 100 \%
$$

where $Q_{\mathrm{i}}$ is the theoretical maximum number of imprinted sites on MIM, which can be calculated from the maximum immobilized template protein and the removal efficiency during membrane synthesis, and $C_{\mathrm{m}}$ and $C_{\mathrm{n}}$ are the apparent maximum number of binding sites from the rebinding test on the MIMs and the NIMs, respectively. The imprinting efficiencies were thus calculated to be $98 \%$ and $76 \%$ for MIM $_{\mathrm{BSA}}$ and $\mathrm{MIM}_{\mathrm{Lys}}$, respectively. The slightly lower imprinting efficiency of $\mathrm{MIM}_{\mathrm{Lys}}$ can be attributed to the smaller size of Lysozyme as compared with BSA. In order to remove the template, the optimum thickness of the MIP layer should be controlled to be less than the size of Lysozyme. Due to the thin imprinting layer of only $0.7 \mathrm{~nm}$, it is highly possible that some parts of the coated layer may be too thin to suitably imprint the shape of lysozyme.

Rebinding kinetic. Rebinding kinetic is an important index for practical MIM application. Adsorption processes are often accompanied by other processes like conformational changes or lateral interaction changes, resulting in a delay in reaching adsorption equilibrium for the system. As observed in Fig. 4, adsorption equilibrium was reached quickly, within $2 \mathrm{~h}$ for two non-imprinted membranes NIM $_{\mathrm{BSA}}$ and $\mathrm{NIM}_{\mathrm{Lys}}$, but $5 \mathrm{~h}$ for the $\mathrm{MIM}_{\mathrm{BSA}}$ and $4 \mathrm{~h}$ for the $\mathrm{MIM}_{\mathrm{Lys}}$ respectively, suggesting that adsorption might have occurred mainly on the surfaces of the membranes. In this process, the most available binding sites were first occupied followed by a decreasing rate until the system reaches a pseudo-steady state. Interestingly, both $\mathrm{MIM}_{\mathrm{BSA}}$ and $\mathrm{MIM}_{\mathrm{Lys}}$ underwent a sudden increase in adsorption

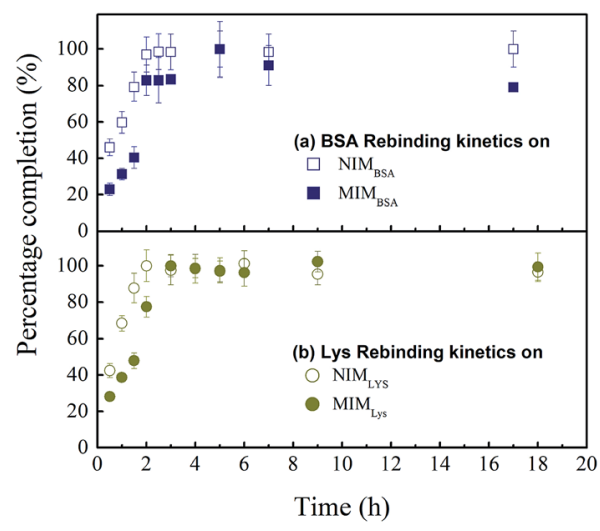

Fig. 4 Protein rebinding kinetic behaviour of MIMs and NIMs: (a) BSA rebinding on $\mathrm{NIM}_{\mathrm{BSA}}(\square)$, and $\mathrm{MIM}_{\mathrm{BSA}}(\square)$; (b) lysozyme rebinding on NIM Lys $_{\text {L }}(C)$ and MIM Lys $(\odot)$. Values represent mean \pm standard deviation (error bars) with $n=3$. 
speed between 1.5 and 2 h. It had been pointed out by van Tassel $^{\mathbf{4 4}}$ that protein adsorption kinetics was history dependent, i.e. the protein molecules that were first adsorbed might act as templates or nucleating sites to accelerate the adsorption of more protein molecules. On the other hand, the adsorption equilibriums of the NIMs were reached faster than those of the MIMs, which could be attributed to the much lower and nonspecific adsorption capacity of the NIMs as well as the time required for the recognition of template protein on the MIMs. ${ }^{38}$

Adsorption isotherm. Adsorption isotherm was investigated via template protein adsorption at various protein concentrations. The Data was fitted to the Langmuir isotherm and the Freundlich isotherm (at lower concentration range) with eqn (1) and (2). Fitting results were shown in Fig. 5 and Table 1 . It can be seen that the $Q_{\max }$ value of MIMs are higher than that of NIMs indicating a higher binding sites density on the MIMs than NIMs. The dissociation constants $k_{\mathrm{d}}$ of MIMs are lower than those of NIMs indicating higher affinities of template proteins towards MIMs. Besides, the value of $k_{\mathrm{d}}$ for $\mathrm{MIM}_{\mathrm{BSA}}$ $\left(5.88 \mathrm{nmol} \mathrm{ml}{ }^{-1}\right)$ is much lower than that of $\operatorname{MIM}_{\mathrm{lys}}(46.33 \mathrm{nmol}$ $\mathrm{ml}^{-1}$ ) suggesting a higher template affinity of $\mathrm{MIM}_{\mathrm{BSA}}$ than $\mathrm{MIM}_{\text {lys. }}$.

The Freundlich isotherm fits better than the Langmuir isotherm especially for MIMs at lower concentration range. The Freundlich parameter $m$ of $\mathrm{MIM}_{\mathrm{BSA}}$ and $\mathrm{MIM}_{\mathrm{lys}}$ are 0.277 and 0.815 respectively.

Competitive rebinding tests. Competitive rebinding tests were conducted in a binary BSA-Lys protein solution, where a non-template protein was employed as an adsorption competitor. As, shown in Fig. 6, the difference in protein adsorption between the $\mathrm{NIM}_{\mathrm{BSA}}$ and the $\mathrm{NIM}_{\mathrm{Lys}}$ was insignificant; however, the template protein adsorption on the MIMs was significantly higher than the non-template protein as well as both proteins on the NIMs. The separation factor of MIM $_{\text {BSA }}$ was calculated to be 32 (BSA to Lys), while the separation factor of $\mathrm{MIM}_{\mathrm{Lys}}$ was 3.6 (Lys to BSA), indicating that both $\mathrm{MIM}_{\mathrm{BSA}}$ and $\mathrm{MIM}_{\text {Lys }}$ possess high recognition ability towards their template molecules in the presence of competitors.

\section{Permeation performance and mechanism}

Permeation experiments. Permeation experiments were conducted to further investigate the specificity of MIM for the template molecule, using the binary mixture of BSA and
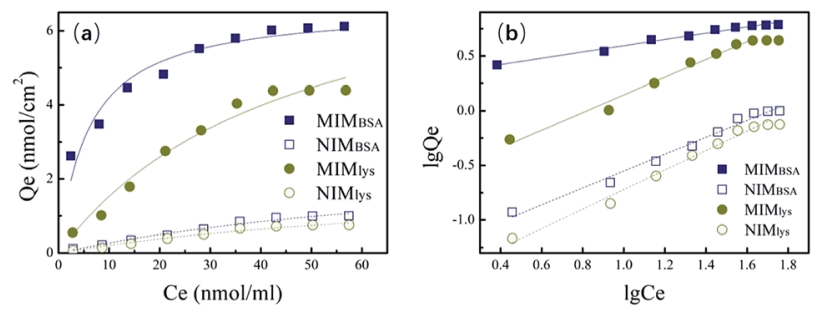

Fig. 5 (a) Equilibrium adsorption capacity $\left(Q_{e}, \mathrm{nmol} \mathrm{cm}^{-2}\right)$ vs. free protein concentration $\left(C_{e}, \mathrm{nmol} \mathrm{ml}^{-1}\right)$, and data fitted to Langmuir isotherm; (b) $\lg Q_{\mathrm{e}} v s . \lg C_{\mathrm{e}}$, and data fitted to Freundlich isotherm. lysozyme at the same molar concentration of $36 \mathrm{nmol} \mathrm{ml}{ }^{-1}$. The mean pore diameters on membrane skin layer for MIM $_{\mathrm{BSA}}$, $\mathrm{MIM}_{\text {lys }}, \mathrm{NIM}_{\mathrm{BSA}}$ and $\mathrm{NIM}_{\text {lys }}$ are 14.5, 19.6, 18.0 and $22.9 \mathrm{~nm}$ respectively (Table $\mathrm{S} 2 \dagger$ ). As was expected, both BSA and lysozyme molecules were detected in the strip chamber when NIMs were used (Fig. S5 $\dagger$ ), because NIM $_{\text {BSA }}$ and NIM $_{\text {Lys }}$ had mean pore diameter of $\sim 18 \mathrm{~nm}$ and $\sim 23 \mathrm{~nm}$ respectively, which was much larger than the Stokes radius of both BSA (4.5 $\mathrm{nm}$ ) and Lys $(1.9 \mathrm{~nm})$. The MIM $_{\mathrm{BSA}}$ exhibited surprisingly excellent competence to separate a BSA-Lys binary mixture with a negligible permeation of BSA and a high permeation rate of lysozyme. Both the BSA concentration and the Lysozyme concentration in the feed chamber decreased with time (Fig. 7a). In the strip chamber, only trace amount of BSA could be found even after $48 \mathrm{~h}$, although the MIM $_{\mathrm{BSA}}$ has a mean pore size of $14.5 \mathrm{~nm}$ which should also be large enough for both proteins to pass through. This could partially be explained by the separation mechanism of MIMs, ${ }^{26}$ where the high selectivity of membranes would be achieved by retarding of the permeation of the template molecules (i.e. BSA) until saturation of the imprinted sites was reached. However, the adsorption equilibrium time for BSA was found to be about $8 \mathrm{~h}$ (Fig. 7a), which was $3 \mathrm{~h}$ longer than that in the competitive batch adsorption. Thus, it is hypothesized that another reason for the long and sustained separation performance of the MIM $_{\text {BSA }}$ is that the BSA molecules accumulate both on the skin layer and in the pores of the membrane during permeation causing the pores to become smaller. This phenomenon is similar to membrane fouling which is common in membrane separation processes and may play a positive role in prolonging the saturation time of BSA adsorption and maintaining a high purity of lysozyme in the other chamber. It was found that, in Fig. 7b, the permeation rate of Lys dropped from 1.7 $\mathrm{nmol} \mathrm{cm} \mathrm{cm}^{-2} \mathrm{~h}^{-1}$ to $0.8 \mathrm{nmol} \mathrm{cm} \mathrm{cm}^{-2} \mathrm{~h}^{-1}$ after $\sim 8 \mathrm{~h}$ permeation when the BSA-adsorption equilibrium was reached. Nonetheless, even after the imprinted sites on MIM $_{\mathrm{BSA}}$ were saturated, BSA molecules might still not be able to freely diffuse through the membrane as the pore sizes decreased due to the adsorbed BSA layers.

On the other hand, the separation performance of $\mathrm{MIM}_{\mathrm{Lys}}$ was not as good as MIM $_{\mathrm{BSA}}$. Intrinsically, due to the lower imprinting efficiency of the MIM $_{\text {Lys }}$, the adsorption of lysozyme was not significantly higher than BSA as also found in the batch competitive rebinding test.

The other possible factor was that positive charges on lysozyme under a neutral $\mathrm{pH}$ were unfavorable for adsorption. Comparing the two permeation systems, the electrical charge density of lysozyme was much higher than that of BSA at the neutral permeation condition considering the huge differences of the isoelectric point $(\mathrm{pI})$ and the molecular weight $\left(M_{\mathrm{W}}\right)$ between BSA (pI: 5.1, $\left.M_{\mathrm{W}}: 67000\right)^{45}$ and Lys (pI: 11, $M_{\mathrm{W}}$ : 14 400). ${ }^{39}$ Consequently, a higher electron repulsion could be expected to exist among the lysozyme molecules in solution and those adsorbed on the $\mathrm{MIM}_{\mathrm{Lys}}$ compared with that of the BSA and $\mathrm{MIM}_{\mathrm{BSA}}{ }^{46}$

Permeation mechanism. It is worth noting that the adsorption capacity of the template proteins on MIMs in the 
Table 1 Langmuir adsorption isotherm parameters and Freundlich adsorption isotherm parameters for MIMs and NIMs

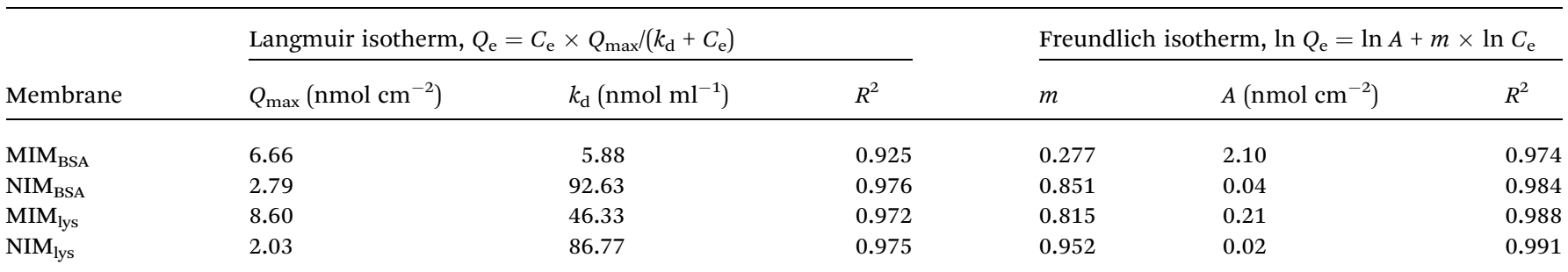

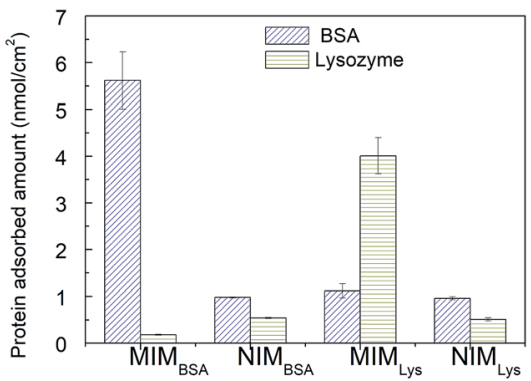

Fig. 6 Proteins competitive adsorption amount on MIMs and NIMs. Values represent mean \pm standard deviation (error bars) with $n=3$.

permeation test was much higher compared with that in the competitive rebinding test; i.e. MIM $_{\mathrm{BSA}}$ was about 9 times higher, and $\mathrm{MIM}_{\mathrm{Lys}}$ was about 4 times higher. The possible reason might be that the imprinted polymer was formed not just on the surface but also beneath the skin layer in the porous structure of CA membranes, as previously observed in FESEM images, thus forming more imprinted binding sites for the template proteins. The distributions of protein
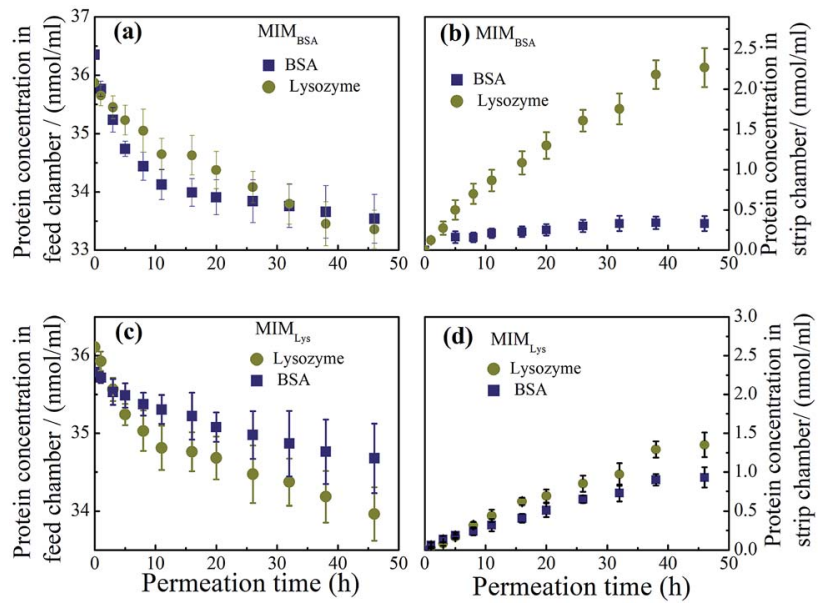

Fig. 7 Protein concentration profiles in (a) the feed chamber and (b) the strip chamber of the permeation device with MIM $M_{B S A}$ during permeation test ( Lys, $\square$ BSA); protein concentration profiles in (c) the feed chamber and (d) the strip chamber with MIMLys during permeation test (- Lys, $\boldsymbol{B S A}$ ). Values represent mean \pm standard deviation (error bars) with $n=3$. adsorption sites along the cross section of the membrane after permeation were investigated through the nitrogen distribution profiles obtained by EDX. A higher quantity of protein was found just beneath the skin layer in the MIMs after permeation than after only adsorption (see ESI Fig. S6†).

To further verify the above hypothesis of existence of the imprinted sites beneath the skin layer of MIMs, two pieces of MIM $_{\text {BSA }}$ bound with BSA-FITC conjugates were imaged with a confocal laser scanning microscope. One MIM $_{\mathrm{BSA}}$ was after $48 \mathrm{~h}$ in the competitive rebinding test; and the other MIM $_{\text {BSA }}$ was after $48 \mathrm{~h}$ in the permeation test with BSA-Lys binary solution. From Fig. 8, it can be observed that more BSA-FITC conjugates were adsorbed on the top layer of $\mathrm{MIM}_{\mathrm{BSA}}$ after permeation than after rebinding. In addition, BSA-FITC conjugates adsorbed onto the inside layer of the porous substrates after permeation test. These sites were less accessible to BSA-FITC conjugates during the rebinding test.

\section{Permeation purification from bacterial lysate}

To better mimic the complexity and diversity of a real industrial protein purification, MIM $_{\mathrm{BSA}}$ was applied to a complex mixture consisting of BSA, lysozyme and bacterial lysate which was composed of proteins, lipids and nucleic acids. From Fig. 9, both the concentration of lysozyme and bacterial lysate increased in the strip chamber with a permeation rate of 0.85 nmol cm${ }^{-2} \mathrm{~h}^{-1}$ and $27 \mu \mathrm{g} \mathrm{cm}^{-2} \mathrm{~h}^{-1}$ respectively, and only negligible amount of BSA could be found in the strip chamber even after $48 \mathrm{~h}$. These results illustrated that template BSA was successfully separated from a multicomponent mixture with a high flux of other components. Thus, the protein imprinted membrane possesses a wide potential in the application of protein purification due to its high specification and selectivity in a complex system.

Reusability of the protein imprinted membranes was also tested. The adsorbed protein after the rebinding tests and the protein residue after protein removal experiments were characterized by XPS. As shown in Fig. S7, $\uparrow$ the adsorbed amounts of proteins remained the same even after the third rebinding cycle. Specifically, after the third rebinding or removal, the nitrogen element contents on the surface of MIM can still go up to or decrease to almost the same amount as the first rebinding, indicating good reusability of the MIM. 

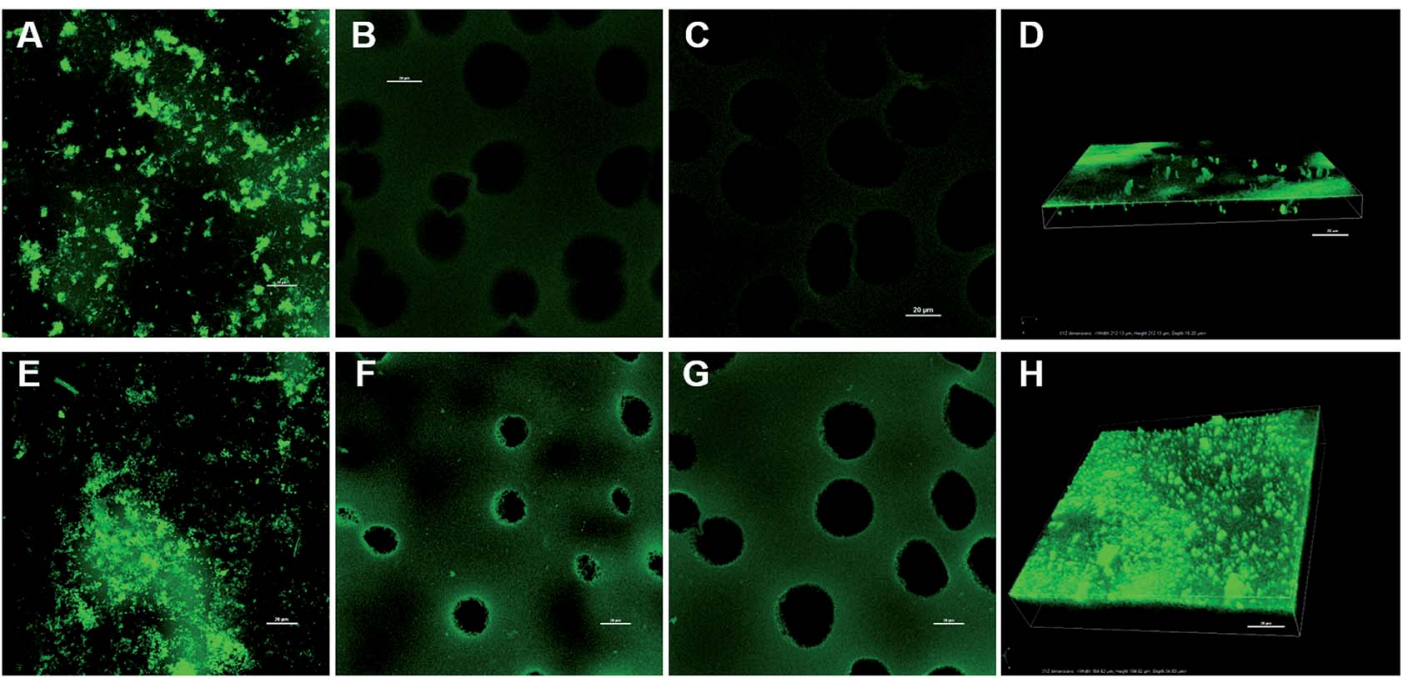

Fig. 8 Confocal laser scanning microscope images of MIMBSA adsorbed with BSA-FITC. (A) Top surface, (B) inside layer I, (C) inside layer II, and (D) volume view of the MIMBSA adsorbed with BSA-FITC after $48 \mathrm{~h}$ of rebinding test; (E) top surface, (F) inside layer I, (G) inside layer II, and (H) volume

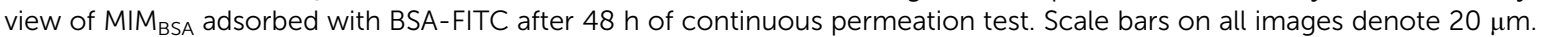
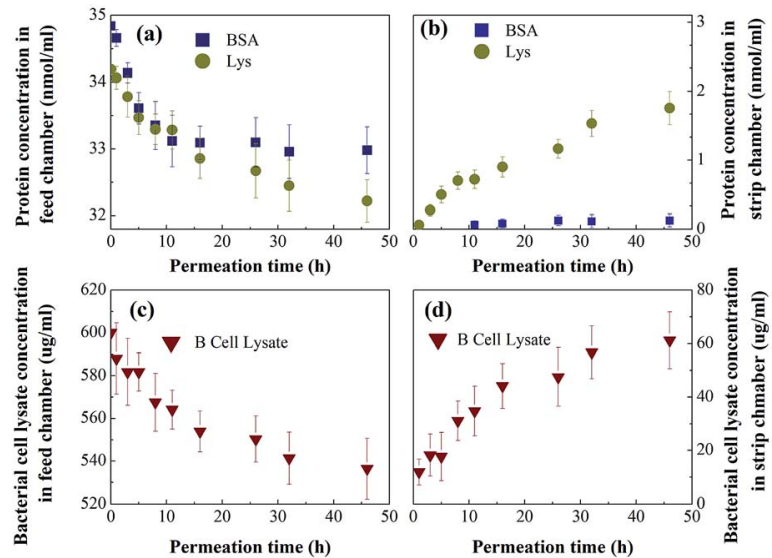

Fig. 9 Protein (o Lys, $\square$ BSA) concentration profiles in (a) the feed chamber and (b) the strip chamber, and the bacterial cell lysate $(\boldsymbol{\nabla})$ concentration profile in the (c) feed chamber and the (d) strip chamber with MIM $\mathrm{BSA}_{\mathrm{A}}$ during the permeation tests. Values represent the mean \pm the standard deviation (error bars) with $n=3$.

\section{Conclusions}

We have shown a well-controlled molecular imprinting method for MIM fabrication. It is based on a simple yet elegant modification of a conventional cellulose acetate membrane, thus enabling common membranes to be used for highly effective protein separation. The above results showed that the protein separation was characterized in detail using adsorption and also continuous assays to elucidate the mechanism of this membrane imprinting method. This work documents that a combination of the specific recognition ability of a molecular imprinted polymer and the size-exclusion effect of a membrane during permeation synergistically enhance protein separation performance in terms of purity. Finally, we have shown that this novel membrane has the ability to separate protein from a complex protein mixture with a high flux thus making it suitable for industrial applications in protein purification. Although only BSA and lysozyme are used as target template in this study, this surface imprinting technique has demonstrated the great potential and viability for the preparation of proteinimprinted membranes using a wide range of other target template molecules.

\section{Conflicts of interest}

The authors declare no competing financial interests.

\section{Acknowledgements}

The authors appreciate the National Natural Science Foundation of China (NSFC No. 51803176) and NUS Foundation (R279000249646) for financially supporting this research. Special thanks are given to Dr Jingnan Luo and Dr Shirlaine Koh for their suggestions and help in this work.

\section{References}

1 L. Chen, X. Wang, W. Lu, X. Wu and J. Li, Chem. Soc. Rev., 2016, 45, 2137-2211.

2 Y. Zhang and S. N. Riduan, Chem. Soc. Rev., 2012, 41, 20832094.

3 C. Alvarez-Lorenzo and A. Concheiro, J. Chromatogr. B: Anal. Technol. Biomed. Life Sci., 2004, 804, 231-245.

4 R. Kecili and C. M. Hussain, Int. J. Anal. Chem., 2018, 8503853.

5 J. Wang, Q. Xu, W. W. Xia, Y. Shu, D. Jin, Y. Zang and X. Hu, Sens. Actuators, B, 2018, 271, 215-224.

6 W. S. P. Carvalho, M. Wei, N. Ikpo, Y. Gao and M. J. Serpe, Anal. Chem., 2018, 90, 459-479. 
7 J. Wackerlig and R. Schirhagl, Anal. Chem., 2016, 88, 250261.

8 H. Wang, Q. Xu, J. Wang, W. Du, F. Liu and X. Hu, Biosens. Bioelectron., 2018, 100, 105-114.

9 A. Katz and M. E. Davis, Nature, 2000, 403, 286-289.

10 M. J. Whitcombe, I. Chianella, L. Larcombe, S. A. Piletsky, J. Noble, R. Porter and A. Horgan, Chem. Soc. Rev., 2011, 40, 1547-1571.

11 G. De Middeleer, P. Dubruel and S. De Saeger, TrAC, Trends Anal. Chem., 2016, 76, 71-85.

12 C. Yang, X. Yan, H. Guo and G. Fu, Biosens. Bioelectron., 2016, 75, 129-135.

13 Y. Hoshino, T. Miyoshi, M. Nakamoto and Y. Miura, J. Mater. Chem. B, 2017, 5, 9204-9210.

14 J. Wackerlig and P. A. Lieberzeit, Sens. Actuators, B, 2015, 207, 144-157.

15 H.-H. Yang, S.-Q. Zhang, F. Tan, Z.-X. Zhuang and X.-R. Wang, J. Am. Chem. Soc., 2005, 127, 1378-1379.

16 T. Chen, M. Shao, H. Xu, S. Zhuo, S. Liu and S.-T. Lee, J. Mater. Chem., 2012, 22, 3990-3996.

17 X. Xu, P. Guo, Z. Luo, Y. Ge, Y. Zhou, R. Chang, W. Du, C. Chang and Q. Fu, RSC Adv., 2017, 7, 18765-18774.

18 Y. Li, Q. Bin, Z. Lin, Y. Chen, H. Yang, Z. Cai and G. Chen, Chem. Commun., 2015, 51, 202-205.

19 Z. Luo, W. Du, P. Guo, P. Zheng, R. Chang, J. Wang, A. Zeng, C. Chang and Q. Fu, RSC Adv., 2015, 5, 72610-72620.

20 L. Qin, X.-W. He, X. Yuan, W.-Y. Li and Y.-K. Zhang, Anal. Bioanal. Chem., 2011, 399, 3375-3385.

21 J. Wang, L. Tian, Y. Yan, Y. Liu, Y. Zhang and C. Yang, J. Braz. Chem. Soc., 2018, 29, 2-10.

22 X. Q. Cheng, Z. X. Wang, X. Jiang, T. Li, C. H. Lau, Z. Guo, J. Ma and L. Shao, Prog. Mater. Sci., 2018, 92, 258-283.

23 D. Xu, S. Hein and K. Wang, Mater. Sci. Technol., 2008, 24, 1076-1087.

24 D. Y. Xing, S. Y. Chan and T.-S. Chung, Green Chem., 2012, 14, 1405-1412.

25 N. F. Ishak, N. A. Hashim, M. H. D. Othman, P. Monash and F. M. Zuki, Ceram. Int., 2017, 43, 915-925.

26 M. Yoshikawa, K. Tharpa and Ş.-O. Dima, Chem. Rev., 2016, 116, 11500-11528.
27 R. I. Boysen, L. J. Schwarz, D. V. Nicolau and M. T. W. Hearn, J. Sep. Sci., 2017, 40, 314-335.

28 T. Zhu, D. Xu, Y. Wu, J. Li, M. Zhou, T. Tian, Y. Jiang, F. Li and G. Li, J. Mater. Chem. B, 2013, 1, 6449-6458.

29 D. Liu and M. Ulbricht, RSC Adv., 2017, 7, 11012-11019.

30 Y. Wu, M. Yan, J. Cui, Y. Yan and C. Li, Adv. Funct. Mater., 2015, 25, 5823-5832.

31 R.-R. Chen, L. Qin, M. Jia, X.-W. He and W.-Y. Li, J. Membr. Sci., 2010, 363, 212-220.

32 Z. Luo, W. Du, P. Guo, P. Zheng, R. Chang, J. Wang, A. Zeng, C. Chang and Q. Fu, RSC Adv., 2015, 5, 72610-72620.

33 W. Li and J. Y. Walz, Sci. Rep., 2014, 4, 4418.

34 W. Xie, F. He, B. Wang, T.-S. Chung, K. Jeyaseelan, A. Armugam and Y. W. Tong, J. Mater. Chem. A, 2013, 1, 7592-7600.

35 N. Sankarakumar and Y. W. Tong, J. Mater. Chem. B, 2013, 1, 2031-2037.

36 N. Sankarakumar and Y. W. Tong, RSC Adv., 2013, 3, 15191527.

37 R. J. Ansell, in Molecularly Imprinted Polymers in Biotechnology, ed. B. Mattiasson and L. Ye, Springer International Publishing, Cham, 2015, vol. 150, pp. 51-93.

38 C. J. Tan, H. G. Chua, K. H. Ker and Y. W. Tong, Anal. Chem., 2008, 80, 683-692.

39 K. P. Wilson, B. A. Malcolm and B. W. Matthews, J. Biol. Chem., 1992, 267, 10842-10849.

40 Y. Xiao and T.-S. Chung, J. Membr. Sci., 2007, 290, 78-85.

41 U. Böhme and U. Scheler, Chem. Phys. Lett., 2007, 435, 342345.

42 A. Bonincontro, V. Calandrini and G. Onori, Colloids Surf., B, 2001, 21, 311-316.

43 Z. Zhang and B. Wang, J. Appl. Polym. Sci., 2009, 113, 10501062.

44 P. R. Van Tassel, L. Guemouri, J. J. Ramsden, G. Tarjus, P. Viot and J. Talbot, J. Colloid Interface Sci., 1998, 207, 317-323.

45 B. Jachimska, M. Wasilewska and Z. Adamczyk, Langmuir, 2008, 24, 6866-6872.

46 A. Vinu, M. Miyahara and K. Ariga, J. Phys. Chem. B, 2005, 109, 6436-6441. 